Ergo

\title{
The Aesthetic Engagement Theory of Art
}

PATRICK GRAFTON-CARDWELL

University of Massachusetts Amherst

\begin{abstract}
I introduce and explicate a new functionalist account of art, namely that something is an artwork iff the fulfillment of its function by a subject requires that the subject aesthetically engage it. This is the Aesthetic Engagement Theory of art. I show how the Aesthetic Engagement Theory outperforms salient rival theories in terms of extensional adequacy, non-arbitrariness, and ability to account for the distinctive value of art. I also give an account of what it is to aesthetically engage a work that relies on our agential capacity to treat an object as having non-instrumental value, even while the ultimate purpose for our engaging the object is to get something from it.
\end{abstract}

\section{Introduction}

One common approach to defining art has been in terms of an aesthetic requirement: for example, that something is an artwork iff it provides us with aesthetic experiences (or is meant to do so, or is of a kind that normally does), or that something is an artwork iff it has intentionally been endowed with aesthetic properties. ${ }^{1}$ There are a few common commitments underlying definitions of this sort:

1. If something is an artwork, this is because of how it is in itself, not merely because of how it's regarded.

2. What makes something an artwork is what it's for, its function.

1. See Beardsley (1982), Zangwill (1995a) and (1995b), and Carroll (1999: 162) for definitions of art similar to these.

Contact: Patrick Grafton-Cardwell <patrickegc@protonmail.com> 
3. What characterizes the functions of artworks essentially is their aesthetic dimension.

Commitment to (1) and (2) makes something a "functionalist" theory. Abell (2012) distinguishes functionalist theories from "procedural" theories, which deny claims like (1) and (2). ${ }^{2}$ Functionalist approaches are those that say something is a work of art iff it has a particular function. For example, representationalist theories of art say that all art represents, or has content, or is about something. Expressionist theories say that something is art iff it expresses emotion. Formalist theories say that something is art iff it has significant form (or was intended to). And so forth.

Functionalist approaches define art in terms of what artworks are for, what they're ideally able to do. The focus is thus on what artworks are actually like in themselves. This focus is consistent with the claim that something is only an artwork (or only becomes so) within a social context. Some functions (e.g., representation, expression, or the provision of aesthetic experience) plausibly require an audience to manifest, and could plausibly only be granted to an object by an artist. Functionalist approaches thus needn't deny that an artistic community plays an essential role in determining the function of the artwork. They just don't allow the question of whether something is an artwork to be reduced to the question of what attitude people have towards it.

Not every theorist who has endorsed something like (1) has explicitly formulated their theory of art in terms of the notion of function. So, not every theorist obviously or explicitly accepts (2). It's not hard to give a functionalist redescription of most any theory that's in agreement with (1), however. I'll thus stick to the course-grained distinction between functionalist and procedural approaches.

Commitment to (3) is what distinguishes aestheticist theories of art from other versions of functionalism, for example, representationlist, expressivist, or formalist theories. I'm drawing crude distinctions here. Some theories aren't neatly categorized into one of these divisions (e.g., Eldridge 1985 calls his theory an aesthetic theory, but posits that every artwork has both a form and a content). Regardless, I'll proceed under the assumption that aestheticist theories of art are a subclass of functionalist theories, and that any theory that endorses (3) or something sufficiently similar should be classified as an aestheticist theory of art.

My goal is to defend a new aestheticist theory. Unlike some of the theories I'm shoehorning into the functionalist camp, my theory is explicitly functionalist.

2. See also Davies (1991: 31-36) for a discussion of procedures and a contrast of procedures versus functions as they pertain to our definition of art. 
I take it that it's something about an object's function that makes it an artwork. I am also in agreement with (3): my theory is an aestheticist theory. I won't say, as some have, that all art has some aesthetic function primarily. That is, I won't claim that all (or only) art has the function of providing us with aesthetic experiences, or of exhibiting aesthetic properties, or any other aesthetic function in particular. It's been the downfall of most functionalist theories of art that they try to identify a single common function of all art. Artworks are many kinds of things, with many disparate functions.

Instead, I identify an aesthetic requirement on the fulfillment of the function of any artwork. That is, if something is an artwork, this is in virtue of a higherorder property of its function, an aesthetic requirement that must be met for that thing's function to be fulfilled.

That's enough background to state the theory.

Aesthetic Engagement Theory: For any $x, x$ is an artwork iff the fulfillment of $x^{\prime}$ s function by a subject $S$ requires that $S$ aesthetically engage $x$.

On the Aesthetic Engagement Theory, what makes something an artwork is the fact that one can't interact with it in the way it's meant to be interacted with (i.e., in the way it's for) unless one aesthetically engages it. The slogan version of the theory: "artworks are the things that demand aesthetic engagement." Obviously it will be important to explicate the notions of function and aesthetic engagement. I'll do this later, when I present the theory in full.

Here's what follows. In §2 I examine some problems that have historically faced functionalist accounts of art, with a special focus on aestheticist accounts, since that's my camp. In \$3 I examine institutional accounts, focusing on an important recent version of institutionalism offered by Abell (2012). I argue that institutional accounts still face intractable problems of their own. In examining the ways institutionalism and other versions of aestheticism have failed, I'll gradually build a list of desiderata for a theory of art: we want the theory to be extensionally adequate, non-arbitrary, and we want it to explain what makes art valuable. In $\S_{4}$ I present the Aesthetic Engagement Theory again, showing how it satisfies these desiderata. In the process of presenting the full theory, I provide a defense of the idea that all artworks have functions, as well as a full account of what it is to aesthetically engage an artwork.

\section{Problems with Aestheticism}

Traditional aestheticist theories of art try to give a definition of art in terms of some kind of functional requirement involving aesthetic properties or aesthetic 
experience. Following Adajian (2018), I'll consider two such theories, those articulated in Beardsley (1982) and Zangwill (1995b). ${ }^{3}$

Take Beardsley first.

I say that an artwork is either an arrangement of conditions intended to be capable of affording an experience with marked aesthetic character or (incidentally) an arrangement belonging to a class or type of arrangements that is typically intended to have this capacity. (Beardsley 1982: 299)

'Arrangement of conditions' here, I take it, is meant to be a catch-all for the variety of kinds of things artists in fact present us with, which include significant variation in physical and artistic media, as well as apparent ontological variety. 4 Beardsley's view is that artworks are one of two kinds of things. Either they are explicitly intended to be capable of affording us experiences with marked aesthetic character (I'1l just call these "aesthetic experiences" while discussing Beardsley's view), or they are of a kind the instances of which are normally intended to be capable of this.

Abell (2012: 672) points to what has been a recalcitrant problem for functionalist approaches to defining art. "A problem that faces all these proposals is that many artworks simply do not seem to have the functions at issue." Functionalist accounts often seem too narrow, excluding objects as artworks that are intuitively so.

Beardsley's definition is no exception. Many avant-garde artworks such as Duchamp's Fountain, John Cage's 4'33", and Robert Barry's All the things I know but of which I am not at the moment thinking - 1:36 PM; June 15, 1969 do not seem to fit Beardsley's definition. ${ }^{5}$ They are arrangements of conditions selected by

3. For an important, non-aestheticist version of functionalism, see Stecker (1996). Stecker's theory is that something is a work of art at time $t$ iff either (a) it is in one of the central art forms at $t$ and is made with the intention of fulfilling a function art has at $t$ or (b) it is an artifact that achieves excellence in fulfilling such a function, whether or not it is in a central art form and whether or not it was intended to fulfill such a function. I ignore Stecker's view here for two reasons. First, I think the objections that apply to both functionalist and proceduralist views will apply to Stecker's view. Because Stecker builds the notion of "the central art forms" into his definition of art, he opens himself up to the charges of arbitrariness typically aimed at procedural approaches. Because he seemingly requires there to be a small set of functions common to all artworks in the central arts, he opens himself up to the problems of extensional adequacy typical for functional approaches. Regardless of whether my suspicions about Stecker's theory are well founded, since I hope to develop an aestheticist view, the more helpful comparison is with other versions of that approach.

4. For a helpful examination of ontological variety in (especially contemporary) art, see Irvin (2008).

5. It's not only avant-garde works that Beardlsey's view seems to exclude, though. His considered account of aesthetic experience requires an aesthetic experience to have what he calls "object 
their artists specifically for the purpose of avoiding an experience with marked aesthetic character. Moreover, Fountain and All the things I know but of which I am not at the moment thinking - 1:36 PM; June 15, 1969 seem to belong to artkinds like readymade and conceptual art, which are not classes of arrangements typically intended to have the relevant capacity. ${ }^{6}$

Take Zangwill (1995b) next. Zangwill holds what he calls the Creative THEORY of art.

Creative Theory: Something is a work of art if and only if someone had an insight that certain aesthetic properties would be determined by certain nonaesthetic properties; and because of this, the thing was intentionally endowed with the aesthetic properties in virtue of the nonaesthetic properties as envisaged in the insight. (Zangwill 1995b: 307)

Zangwill takes the Creative Theory to best explain why we value art: artworks are the manifestations of aesthetic insight. The idea that we are interested in aesthetic properties that are a result of aesthetic insight is a better explanation of the value of art (and of our interest in it) than any theory of art that says it does something that could be substituted by non-art (like representation or expression, for example).

Like Beardsley's, Zangwill's theory seems to suffer from a problem of narrowness. It apparently excludes children or aesthetic amateurs from making art, since they won't have the kind of aesthetic insight required to know what aesthetic properties will be determined by what nonaesthetic properties. It also seems to exclude art that involves a significant degree of chance in its composition: if an artist allows the aesthetic properties of a work to be determined through an aleatoric process, rather than by a special insight, they won't seem to be exercising the right kind of aesthetic creativity to make art, according to the Creative Theory.7

directedness" and at least three of the following four features: felt freedom, detached affect, active discovery, and wholeness (Beardsley 1982: 288-89). There is a lot going on in this characterization of aesthetic experience, and I'll make no attempt to explicate it here. However, if this is what Beardsley has in mind by an aesthetic experience, then an aesthetic experience must either possess all these features, or most of the features to a very high degree. But this will exclude many things we often count as art. For example, much ornamental or design art (e.g., the Portuguese Azulejo) doesn't seem liable to induce a marked experience of felt freedom, detached affect, active discovery, or wholeness.

6. Whether Cage's $4^{\prime} 33^{\prime \prime}$ is in fact a piece of music and thereby satisfies the latter half of Beardsley's definition is a matter of live debate. For an argument that it is not music, but in fact performance art, see Dodd (2017). For a helpful deep dive into the history of Fountain and the ontology of readymades, see Evnine (2013).

7. Thanks to Justin Mooney for the point about artmaking that involves chance. 
Zangwill's theory also faces a problem of broadness. The Creative Theory has the result that any time someone endows something with aesthetic properties as a result of a special kind of aesthetic insight, they've made a work of art. But it seems that many people have the insight and put it to effect all the time when creating non-art. For example, someone might have the insight that certain non-aesthetic properties (e.g., a certain size and shape and material composition) will determine certain aesthetic properties (e.g., being cool, being sleek, or, generally, being beautiful) and this insight will play a role in the way they choose to design a mass-produced car or toaster. ${ }^{8}$ Very few of us will want to say that cars, toasters, or anything else that's designed and mass-produced is (or even can be) a work of art. ${ }^{9}$ But if the Creative Theory is right it's hard to see why not. De Clercq (2009) points out that if the Creative Theory is right, "everyday hygienic activities such as washing and combing one's hair, brushing one's teeth (with whitening tooth paste), shaving, and filling the laundry machine" could count as artistic activities. A certain aesthetically pleasing arrangement of furniture in your living room could count as art, if only you arrange it with the right insight.

In general, then, aestheticist theories of art face problems of extensional adequacy. Zangwill (1995a) warns against worshipping the god of extensional adequacy over the god of explanation, but clearly an explanation that misses the extensional mark by a mile is not much good.

\section{Institutional Alternatives}

The main alternative to functionalist approaches to defining art have been what Abell (2012) and others call "proceduralist" approaches. These define artworks in terms of the procedure by which they are produced, rather than by their function. Something is an artwork in virtue of some facts about how it came about or, generally, its history, not because of what it's like in itself.

A prominent species of proceduralism is institutionalism. ${ }^{10}$ Institutionalist definitions are those that hold that something is an artwork in virtue of some

8. I should say here that at no point do I plan to give an account of what an aesthetic property is. It's hard enough to give a theory of art. As is common practice, then, I'll just give some examples of aesthetic properties: these are properties like being graceful, being balanced, being dynamic, being elegant, being ugly, or being ungainly. See Sibley (1959; 1965), De Clercq (2002), and Goffin (2019) for characterizations of aesthetic properties.

9. Zangwill does claim that these things are art, even if not fine art. So, apparently, does Munro (1967). Thanks to an anonymous reviewer for pointing this out to me. These theorists are among what is likely a significant minority. For most of us, mass-produced appliances are out.

10. The other most prominent species of proceduralism is historicism about art, the view that something is an artwork iff it is intended to be regarded in some way that artworks of the past were properly usually regarded. For a prominent version of historicism, see Levinson 
relation(s) it bears to an art institution. The great hope of institutionalism is to achieve the extensional adequacy that functionalist theories inevitably seem to lack. ${ }^{11}$ For example, the institutionalist can easily account for avant-garde art: it's a product of the right kind of institution (or plays the right role in that institution, or ... of course the details vary according to the version of institutionalism under consideration). On the other hand, cars and toasters aren't art for institutionalism: they aren't products of an art institution.

Of course, there have been plenty of complaints about institutional theories. They face a kind of aesthetic variant of Euthyphro's dilemma. Does the artworld confer the status of candidate for appreciation on some objects because they are art, or are some objects art because the artworld confers the status of candidate for appreciation on them $?^{12}$ If the institutionalist takes the latter horn, they appear to make art-status arbitrary. We think that being an artwork isn't something as extrinsic as being regarded a certain way. If they take the former horn, they invalidate their theory as an explanation of the nature of art. The question of what makes something art remains.

Institutional theories also seem unequipped to explain the value of art. If art-status amounts to being regarded a certain way by a particular in-crowd, it's

(1979). I ignore historicism here for the same sorts of reasons I'm ignoring alternate versions of functionalism in §2. The objections that typically apply to institutionalist theories usually apply to historicist theories too. Also, institutionalism has seemed to me to hold greater sway recently, so it strikes me as a more effective contrast class. I should note that Iseminger (2004) introduces a view that is similar in some ways to Abell's view. For example, much of Iseminger's focus is on the function of the artworld, which he argues is "to promote aesthetic communication" (Iseminger 2004: 23). I leave Iseminger's view aside, however, for two reasons. First, it's harder to say where Iseminger fits in the landscape of aestheticism versus institutionalism. Iseminger is motivated in part to discuss the nature and function of art institutions and artistic practice, but he also posits that a work of art is good (qua art) insofar as it has the capacity to afford appreciation, an activity that seems at least in part to involve attention to the aesthetic properties of the art object. Second, it's not clear to me what part (if any) of Iseminger's account is meant to be offering a definition. It certainly seems that not all of his project is meant to be definitional. It's harder to make any comparative claims between my own view, Abell's, and Iseminger's without clarity on this issue.

11. Davies (2016: 37) also points out that "The institutional theory is well placed to explain how something could be art even though it is poor in aesthetic value and in other respects." While it seems that some aestheticist theories (e.g., Zangwill's) will have more trouble explaining that phenomenon, some don't seem to have any trouble at all. Beardsley's theory, for example, doesn't seem to have any particular trouble explaining this, since he only requires that something be intended to provide us with an experience with marked aesthetic character. Intentions can surely go largely unfulfilled.

12. This way of formulating the dilemma is obviously directed at Dickie (1974), an early and prominent defender of institutionalism. For a more recent formulation of his view, see Dickie (1984). While I've formulated the dilemma here initially as aimed at Dickie, I think the fundamental point applies to any version of institutionalism, as I'll demonstrate in my discussion of Abell (2012) below. 
not at all clear why we should care about art as art. Zangwill (1995a: 538) has made this point especially clearly:

People think that producing and consuming art is worthwhile. We have an important set of beliefs about the value of art, and about its role in our lives. Among the things we believe about art is at very least that art-making and appreciation is a rational pursuit and not a waste of time. . . . I conclude that a theory of art must make sense of our desires and evaluations concerning art.

If a theory of art doesn't make sense of the fact that we are motivated to make and appreciate art, then it doesn't seem likely to have gotten at what art really is. Institutional theories face this specter, since it's not at all obvious why we should have these motivations if artworks are just objects that have been regarded a certain way by a certain crowd.

Abell (2012) has proposed an institutional theory meant to answer some of these objections. It's worth examining her theory to see how it fares. To get a handle on Abell's definition, one first has to get clear on some notions it depends on, largely borrowed from Searle (1995). On Abell's view, institutional facts are facts about what status functions are collectively assigned to what objects. Examples of status functions include functioning as money or functioning as rank identification. Money cannot function as such in virtue of its physical structure, nor can rank identification (such as stars on a uniform). These things function as they do because people collectively treat them as such.

An institution, according to Abell (following Searle) is a collection of institutional facts that have become "regularized" so as to become a system of constitutive rules. These constitutive rules form the basic structure of facts about what counts as what within the context of the institution. The existence of institutions, on this view, "depends on their being seen to perform some function" (Abell 2012: 682). The only reason that people will consistently assign a set of status functions that apply within like contexts, sufficient for a set of constitutive rules to emerge, is if they believe those rules to have some kind of social value in those contexts.

Abell uses these notions to provide a definition of art institution:

Something is an art institution iff it is an institution whose existence is due to its being perceived to perform certain functions, and these functions form a significant subset of the following: promoting positive aesthetic properties; promoting the expression of emotion; facilitating the posing of intellectual challenges, promoting formal complexity and coherence; facilitating the communication of complex meanings; promoting the 
exhibition of individual points of view; promoting originality; and promoting the exercise of a high degree of skill. (Abell 2012: 683-84)

Art institutions are institutions whose existence depends on the belief (at least initially) that they perform functions we typically associate with art. (The list of functions is borrowed from Gaut 2000.)

That's enough background to state Abell's full institutional theory of art.

Something is an artwork iff it is the product of an art institution, and it directly affects how effectively that institution performs the perceived functions to which its existence is due. (Abell 2012: 686)

A product of an institution, in Abell's sense, is just a thing that results "from the collective assignment of status functions according to the constitutive rules" of the institution (Abell 2012: 684). Products are just the new things that come about (or new statuses that things take on) as a result of applying the constitutive rules of the institution. Not all products directly affect how effectively an institution performs the perceived functions to which its existence is due, though.

Abell claims that artworks are products of an art institution and they directly affect how effectively a given institution performs the perceived functions to which its existence is due (Abell 2012: 685). Artists and art critics are also products of art institutions, in the relevant sense, but Abell (2012: 686) contends that they "do not directly affect the ability of art institutions to perform these functions." On Abell's definition, then, art is a particular kind of product of a particular kind of institution.

Does Abell's theory dodge the typical complaints lodged against institutional theories? Recall the first complaint: the institutional theory either makes art-status arbitrary or it fails to explain it. Previously, I put this in the form of a dilemma. We can rephrase the question in terms more appropriate to Abell's theory: are some objects art because they are products (of the right sort) of art institutions, or are they products (of the right sort) of art institutions because they are art? Clearly, Abell opts for the first horn. She thinks that what explains the fact that something is art is that it's a product (of the right sort) of an art institution.

The relevant concern is whether Abell has avoided the charge of arbitrariness associated with that horn. Part of what makes institutionalism in general seem arbitrary is the claim that only institutions can produce art, so that the solo artist working alone can't produce art in the comfort of their own home (or on a desert island), for their own enjoyment and benefit. Abell's theory retains that feature. Another part of what has traditionally made institutionalist views seem arbitrary is that they've placed no constraints on what artworks actually must be like. Abell's theory seems more modest in this regard. There are no explicit 
restraints here, but the requirement that an artwork has to directly affect an art institution's ability to perform the relevant functions to which its existence is due seems like a promising constraint.

There's reason to worry about the notion of art institution that underlies this constraint, though. First, consider Abell's claim that in order for an institution to be an art institution, it has to be believed (at least initially) to perform certain functions. Khalidi (2015: 99) has argued that "there are social kinds whose nature is such that human beings need not have any propositional attitudes towards them for them to exist." Social kinds of this sort don't depend on our beliefs, thoughts, or attitudes towards them for their existence. It seems plausible that some art institutions belong to this kind of social kind. Rather than thinking that all artworks are just the products of art institutions (which come into existence when enough people come to believe that the institution will perform certain functions of the right kind), it seems much more plausible to say that some art institutions come into existence when there are enough artworks of a certain kind and some social facts about how some group is treating those artworks, regardless of what beliefs or attitudes the members have towards the institution in question.

Think, for example, of a plausible example of one kind of art institution, a local music scene. Lena (2012) discusses scene-based forms of music genres. They are usually locally and virtually organized around a goal of creating community, with attention to codifying the style of their genre and separating themselves from established genre music through technical innovation, dress, and lingo. Local scenes seem to be art institutions. On Abell's theory of art institutions we would have to say local scenes come into existence because some people believe they'll serve the function of promoting positive aesthetic properties and so forth. That may be so in some cases, but in many cases the motivating factor will likely be something much different and unrelated to Abell's list. In the case of a local scene (as Lena 2012 points out) it's often a desire for belonging that motivates the formation of the institution. It seems likely that in many cases the scene will come into existence without anyone forming any beliefs about it at all. That doesn't seem intuitively to undercut the scene's status as an art institution, but on Abell's view it would.

There's also reason to worry about Abell's appropriation of Gaut's cluster of properties in her definition of art institution. Consider, for example, a university. Universities often or always include the following as part of their functions:

- promoting positive aesthetic properties (by hosting art programs as part of their suite of academic activities, say),

- facilitating the posing of intellectual challenges,

- promoting formal complexity and coherence, 
- facilitating the communication of complex meanings,

- promoting the exhibition of individual points of view,

- promoting originality, and

- promoting a high degree of skill.

There's no obvious reason, then, why a university shouldn't count as an art institution, according to Abell's definition. The same could be said of many marketing or design firms. Abell's account of art institutions was supposed to offer extensional adequacy without arbitrariness, but it appears to offer neither. Lurking within the account are similar problems of extensional adequacy that plagued the aestheticist, while the view seems to make arbitrary which institutions (and works) are in or out.

The other objection raised against institutional theories was that they're unequipped to explain the value of art. Why should we care about art (and in a way that tracks the distinctive value of art) if artworks are merely the products of institutions? Abell takes on this explanatory burden. Her response is to point to the fact that we care about what we believe art institutions accomplish, and artworks are the things that directly affect their ability to accomplish these things, so we care about artworks insofar as they enable art institutions to do what they are supposed to. "Artworks are good as artworks - they have artistic value-insofar as they have the tendency to improve how well the institutions of which they are products perform the functions that make them art institutions" (Abell 2012: 687-88). If an artwork contributes greatly to the function of the institution of which it's a product, then we have good reason to care about it as art.

This account of the value of art doesn't seem to fit our actual experience of valuing art, though. Many people value artworks as art without caring a whit about the institutions of which the artworks are a product. Imagine going to the Met and sitting in front of Corot's Diana and Actaeon (Diana Surprised in Her Bath) (1836). You might appreciate how imposing it would be to compose a painting of such size; or the formal complexity introduced by the angles of the trees, pond, and rocks against the sky; or maybe the delightful contrast of the light, silvery background against the dark and bold foreground. Instead, imagine the content of your appreciation being the thought, " $\mathrm{I}$ ' $\mathrm{m}$ so glad this painting is serving the mission and vision of the Met." Certainly there is a way in which these forms of appreciation could mutually reinforce each other, but for most of us the latter thought will never come to mind, and for many it won't even be a dispositional concern. Some people don't care about the function of the Met, but that doesn't stop them from valuing the art in it. We can even imagine a world in which the Met has become the most corrupt art institution. You could be sitting there, planning to burn down the building in protest, but trying to puzzle out how to save 
the Corot from the fire. Your appreciation of the Corot would have nothing to do with the institution to which it belongs.

My claim is not that Abell has failed to identify an aspect of art we might care about (viz. that an artwork can serve an institution). It's just that she has clearly not captured all of what is in fact valuable about art as art. Some people might value artworks because of how they contribute to the function of art institutions, but many don't, and even of those who do there are some who also (rightly) value artworks because of what the artworks themselves can offer us.

To summarize, I see three problems for Abell's institutional theory. First, Abell's theory seems to make art-status arbitrary by only allowing the products of institutions to be artworks. Second, there's reason to worry about Abell's understanding of art institution. Last, while Abell's theory can explain the value of art in part, it can't explain the value of art in full: it can't explain why we care about art in itself. Looking closely at Abell's theory allowed us to see how even a recent and sophisticated version of institutionalism has trouble avoiding the pitfalls common to institutionalist theories generally.

\section{The Aesthetic Theory of Art on Display}

Examining the foregoing theories of art has allowed us to construct a short list of desiderata for a theory of art. We want a theory of art that is extensionally adequate, that avoids arbitrariness, and that explains why art is valuable in itself. Here I'm going to re-present the Aesthetic Theory of Art and show how it satisfies all of those desiderata.

First let me restate the Aesthetic Theory of Art.

Aesthetic Engagement Theory: For any $x, x$ is an artwork iff the fulfillment of $x^{\prime}$ s function by a subject $S$ requires that $S$ aesthetically engage $x$.

An object's function, as I'm conceiving of it, is what it's for. The Aesthetic Engagement Theory requires that every artwork is for something. ${ }^{13}$ On the one

13. In the philosophical literature on artifacts, there are competing accounts of what determines an object's function, and even of what functions are. For some philosophical accounts of function, see Cummins (1975), Millikan (1984; 1995; 1999), Preston (2009), and Wright (1973). For a collection of papers discussing biological vs. artifactual functions, see Krohs and Kroes (2009). Some theorists of artifacts subscribe to function essentialism about artifacts, the view that all artifacts are essentially functional objects. Juvshik (2021: 3-4) divides this view into two separate theses:

Artifact Condition: Necessarily, for all $x$, if $x$ is an artifact, then there's some function $F$ such that $x$ has $F$. 
hand, this might not seem that controversial. It's commonly held that artworks are intentional objects. That is, as Mag Uidhir (2013: 3) argues, "regardless of one's preference for any particular brand of art theory . . . the one constant must be that intention-dependence is a necessary condition for something's being art."

It's natural to move from the view that all art is intention-dependent to the view that art has a function, since the view that intentions determine the functions of artifacts is also quite plausible. On the other hand, it has often been said in the history of aesthetics that art must be made "for art's sake", and that the correct form of engagement with art is an attitude of disinterested attention. Any function foisted upon an artwork by outside the world of art has sometimes been seen as a corruption of the work qua art. This kind of sentiment might seem to militate against the view that all artworks have functions.

I have a couple things to say about this. First, as Wolterstorff (2015) has argued, there is much art that has a function besides merely being disinterestedly attended to. Memorial art, religious art, social protest art, work songs, and street art all have functions that go beyond disinterested attention. ${ }^{14}$ While some art certainly does have the function of being for it's own sake, that is, having a function that is self-referential or satisfiable by interaction with the work alone, not all art is that way. Memorial art is for honoring people, places, and events. Work songs are for making drudgery meaningful. Street art is for making street spaces significant. And so forth. The idea that these forms of art are in some sense deficient as art because the fulfillment of their functions lies outside the work is clearly false.

Second, even art that is for art's sake has a function. The thought that art must be for art's sake wasn't really the thought that art mustn't be for anything, but that it mustn't be for anything outside the domain of art. We can still identify what the artworks that obey this principle are for. The functions of such works

Kind Membership Condition: Necessarily, for all artifact kinds $K$, there is some function $F$ which all and only members of $K$ have.

While I'm sympathetic at least to the Artifact Condition, my theory doesn't require anything as strong as function essentialism. Instead, I hold something much weaker.

Function Condition: Necessarily, for all $x$, if $x$ is an artwork, then $x$ is an artifact, and there's some function $F$ such that $x$ has $F$.

The Function Condition is substantive in at least a couple respects. First, it says that all artworks are artifacts. Second, it says that all artworks have functions. I don't expect the first claim to be controversial, nor is it essential for the Aesthetic Engagement Theory. I defend the second claim in what follows. See Juvshik (2020) for a defense of the idea that all artworks are artifacts.

14. Wolterstorff (2015) discusses the functions of memorial art, art for veneration, social protest art, and work songs. On the nature and function of street art, see Riggle (2010). 
might include representation, expression of emotion, the display of formal complexity, or the affording of experiences with significant aesthetic character. The fulfillment of such functions by a subject will require things like looking at, listening to, and in general attending to the work. Even if some work of art is made only for art's sake, this is no reason to think it's functionless.

There's another kind of case that might make us think there can be artworks that have no function. This case comes to light when we consider the seemingly close connection between an artwork's function and the intentions of its artist(s). In general, we think that if an artist has the intention that their work have some function $F$, this will be efficacious in the work's coming to have $F$. However, consider a case in which an artist creates a work merely for the sake of creating. They have no particular thoughts about what they want their work to be for, they just have a hankering to create and so they get to work. Call this the Case of the Aimless Artist. In this case, what is the function of the resultant artwork?

It might be supposed that since the artist has no thought about what the work is for, then there isn't anything it's for. The absence of a function-directed intention is sufficient for the absence of a function. This doesn't seem right though. While function-directed intentions of an artist may be sufficient (in normal circumstances, at least) for determining the function of an object, they aren't necessary. An object can have some function $F$ not in virtue of a maker's intention that the object have $F$, but in virtue of the fact that the maker has made something of a certain kind $K .{ }^{15}$ In the Case of the Aimless Artist, the natural response is to say that in lieu of function-directed intentions, the function of the resultant artwork is determined by the kind of thing it is. Did they make a painting? Then it's for attending to with your eyes. Did they make a sculpture? Same thing. Did they compose a song? Then it's for listening to. Art-kinds have associated functions with an attendant history, and when an artist makes something of a particular kind, in lieu of any function-directed intentions, the object inherits the associated function even if the artist had no occurrent thoughts about what the piece was for.

It's possible to press back here by considering a possibility in which the Aimless Artist makes something that doesn't belong to any established art kind. What should we say then about the function of the resultant work? If the case is one where someone really sets out to make something, but literally intends nothing about what it's for, and doesn't successfully make something of any established kind, then I am fine drawing the line here and saying they'll have failed

15. For more on this kind of idea, see Millikan (1995: 13-14) on "direct proper functions" and Evnine (2016: 119-25) on "kind-associated functions". 
to make art. If someone produces an object that's no kind of thing and that isn't for anything, it seems more plausible to me that they've produced junk than art.

On my view, then, all artworks have functions. Unlike many functionalist theories of art, however, I don't assume that there is some function that is common to all art. Trying to offer a single function of all art is what has traditionally raised the bogeyman of extensional inadequacy. Instead, the Aesthetic Engagement Theory says that all artworks have functions with a certain kind of fulfillment requirement.

For an object's function to be fulfilled by a subject $S$ is for $S$ to interact with the object in the way it's for. A chair's function is fulfilled when someone sits in it. A dance performance's function is fulfilled when some audience members pay attention to the aesthetics of the movement. For there to be a requirement on the fulfillment of the function $F$ of an object $x$ is just for it to be the case that for a subject $S$ to fulfill $F$, there is something that $S$ must do to fulfill $F$ that would not itself fulfill $F .^{16}$ This "something that $S$ must do" is the requirement. A requirement on the fulfillment of the function of a knife (i.e., to cut) by a subject is that the subject hold the knife. A requirement on the fulfillment of the function of a dance performance by some subjects is that they show up. My claim is that every artwork's function has the requirement that in order for it to be fulfilled by a subject $S, S$ must aesthetically engage the artwork.

We need to have a better picture of aesthetic engagement to have the full picture of the theory, then. As a starting point for characterizing aesthetic engagement, I'll follow Nguyen (2019: 1137):

'Aesthetic engagement' here includes our higher-level cognition of aesthetic objects: searching for connections, rethinking interpretations, discovering affective resonances, and so on. It also includes low-level forms of engagement such as perceptual engagement: actively shifting one's attention from one perceptual detail to the next, and then assembling those details into a larger structure. And it includes the way these forms of engagement feed into one another, as my interpretation and affective responses influence where I direct my attention, and vice versa. Aesthetic engagement includes all the perceptual, cognitive, and affective processes we actively deploy on our way to generating an aesthetic judgment.

16. I think different requirements could hold with different modal force, some with mere practical force, some of nomic necessity, and some of metaphysical or logical necessity. The aesthetic engagement theory requires only a weak, pragmatic reading of 'must' for its condition to hold, but it also permits the condition to hold in cases where the requirement holds much more stringently. Thanks to Justin Mooney for raising this question. 
Key here is the idea that aesthetic engagement is linked to certain psychological (perceptual, cognitive, and affective) processes by way of an activity (generating aesthetic judgments) that structures them. The activity of generating aesthetic judgments determines which psychological processes an aesthetically engaged subject is involved in. The psychological processes are what characterize the phenomenology of aesthetic engagement. It's the processes of attentively perceiving, interpreting, and affectively responding to the aesthetic features of an object that give aesthetic engagement a particular phenomenological color distinct from other forms of engagement with the objects in our environment. The thought, in total, is that there's something common to our experience of what it's like to engage a painting, a musical work, or a gourmet meal in the way they're meant to be engaged. The common experience is explained, on this view, by the underlying processes we employ, which are structured psychologically by the common goals we have in interacting with the objects in question.

My characterization of aesthetic engagement is similar to Nguyen's in some ways and departs from it in others. ${ }^{17}$ Like Nguyen, I take aesthetic engagement to involve attending to the properties of an object and responding to them by way of a variety of psychological processes. Like Nguyen, I think this involves higher-level cognition like interpretation and affective response as well as lower-level perceptual engagement. Unlike Nguyen, however, I don't require the end of aesthetic engagement to be an aesthetic judgment. I do require that the properties we attend to in aesthetic engagement be aesthetic properties. (It's not obvious in Nguyen's description of aesthetic engagement whether he thinks this is necessary.) I also diverge from Nguyen in failing to subscribe to his universal generalization about why we aesthetically engage with works.

There are at least a couple reasons I differ from Nguyen here. First, as my discussion of artwork functions above showed, there are are many disparate functions artworks can have. If we're interacting with religious, political, or memorial art, for example, in the way it's meant to function, we won't aim primarily at generating an aesthetic judgment. We'll have other aims, like veneration, the formation of certain politically engaged sentiments, or the honoring of certain people or groups. Second, setting aside the actual functions of artworks, we are free to interact with them under a variety of different motivations. I don't want to make any universal claims here about how or why people interact with art, then. I think the answers to those questions are going to be complex. What Nguyen says about our motivations for making aesthetic judgments seems plausible to

17. Nguyen's interest in discussing aesthetic engagement is (in part) in understanding the value of aesthetic autonomy, the demand that we make of ourselves that our aesthetic judgments be the result our own faculties and abilities rather than the result of testimony. It should be no surprise then that his discussion of aesthetic engagement turns on the activity of generating judgments. I don't take the differences in our characterizations to indicate a fundamental disagreement. 
me insofar as it goes. It's just that we interact with art in a lot of other ways besides generating judgments about it.

On my view, the disparate functions of art objects (and the disparate goals we have in interacting with art) direct aesthetic engagement differently. Objects that are for aesthetic judgment direct aesthetic engagement by getting us to form interpretations about them and affectively respond to them. These goals generally require direct perceptual engagement with the aesthetic properties of the work over a sufficient period of time for an interpretation or response to be well-formed. Objects that are for religious veneration direct aesthetic engagement by getting us to attend to to the symbols they portray and to focus on their significance. This also requires direct perceptual engagement with the aesthetic properties of the object. Objects that are for making drudgery meaningful direct aesthetic engagement by infusing an experience of drudgery with delight, getting us to participate in it, to respond affectively to that delight, and to incorporate it into our work. This once again requires direct perceptual engagement with the aesthetic properties of both the object of delight and the experience of drudgery for the transformation to occur. When we're interacting with an artwork in the way it's meant to be interacted with (i.e., in accord with its function), we have to aesthetically engage it, no matter what it's function is. Artworks demand aesthetic engagement of us. That engagement is directed differently according to the different functions of the works, though.

This account, on which artworks demand aesthetic engagement in accord with their function, is on display in Baxandall (1988), who discusses the function of religious pictures in fifteenth century Italy. Commenting on a sermon by Dominican Fra Michele da Carcano on the topic, Baxandall (1988: 41) says, "If you commute these three reasons for images into instructions for the beholder, it amounts to using pictures as respectively lucid, vivid and readily accessible stimuli to meditation on the Bible and the lives of the Saints." The function of religious pictures, in that particular context, was to be a focus for meditation on stories and people of religious significance. Pictures served this function best because they could be aesthetically engaged. A well-executed picture is easily more lucid, vivid and readily accessible to the layperson than a scriptural text or a hagiography, especially in a context with low rates of literacy. The religious picture can have a profound devotional effect precisely because it allows for connection and engagement on an aesthetic dimension, all while presenting few barriers to accessibility.

This helps us see how aesthetic engagement varies across works of different kinds, but what is common about aesthetic engagement in all cases? We need an account of what makes aesthetic engagement the kind of thing it is. In order to articulate that account, Ineed to introduce one more important distinction, due to Nguyen (2020: 143-44). Nguyen makes a helpful distinction between the artist's 
work and the attentive focus. The former he takes to be the "stable artifact created by the artist," which I've been referring to as the artwork. The attentive focus, Nguyen describes as "the prescribed object of attention for the audience." 18 In most cases the artwork is the prescribed object of attention for the audience. That is, most artworks are accompanied by a prescription that the audience attend to them. ${ }^{19}$ However, some artworks are accompanied by the prescription that the audience attend to something else, for example, that the audience attend to their own activity or to what the work represents or makes reference to. For example, Nguyen (2020: 75) points to social art (also known as "relational aesthetics") as a form of art in which the audience's active response to the work is integral to the work itself, so that the work guides the audience to interact with their community in some new way and to attend to the aesthetic features of the interaction. Likewise, Nguyen (2020) argues games are a kind of art that elicit an activity from the audience and prescribe that the audience attend to their experience of their agency in the midst of that activity.

On the account I have in mind, what is common across all cases of aesthetic engagement is that one's attention is directed to the aesthetic properties of the attentive focus of the work in such a way that the attentive focus is treated as an end in itself. That is, what's common across all cases of aesthetic engagement is a specific way of attending to the aesthetic properties of an object, namely such that we treat the object as worthy of attention for its own sake. In treating an object as worthy of attention for its own sake, we attend to it, and while attending we subject ourselves to it rather than subjecting it to our interests, at least for a time. This is a familiar experience for all of us. In treating another person as worthy of attention for their own sake, we might listen to what they have to say, not because of what we can get from them, but because they are worth listening to in themselves. In such a moment, we subject ourselves to the leading of the other. In treating a work of art as worthy of attention for its own sake, we look at, listen to, or otherwise attend to it, not because of what we can get from it (at least not right then) but because the

18. As Nguyen (2020: $143, n$. 2) points out, the notion of the attentive focus is similar in certain ways to the notion of the "focus of attention" introduced in Davies (2004: 26-27, 50-79). The difference between the two notions, as Nguyen puts it, is that the focus of attention (as Davies articulates it) is always and only generated by the artist. Nguyen's purpose in introducing the concept of the attentive focus is (in part) to draw attention to the times in which the audience is the source of what they are supposed to attend to if they are to interact with the work as it was intended. The artwork, in some cases, guides the audience to generate the attentive focus. Davies's description of the focus of attention precludes the possibility that the audience could generate it, on the other hand.

19. Importantly, these prescriptions are provisional. It's not that one ought, all things considered, to attend to all artworks. It's that if one wants to interact with the artwork in the way it's meant to be interacted with, then one ought to attend to the attentive focus of an artwork. 
work is worth attending to in itself. In such a moment, we subject ourselves to the leading of the work.

A caveat is in order. It's important to note that treating an object as worthy of attention for its own sake doesn't actually require that one consider the object as having final value, full stop. (By 'having final value', I mean having noninstrumental value and lacking instrumental value.) We don't always regard the object of attention with this kind of final value in art. That is, in many cases we adopt a posture of valuing the object of attention this way because doing so gets us some further end we're really aiming at. An example will help here. Let's agree with Wolterstorff (2015: 129) for the moment that the "essential function" of memorials is honoring people, places, and events by "preserving and enhancing memory" of them. If we are fulfilling the function of a particular memorial, then, we are allowing it to preserve or enhance our memory of the person(s), place(s), or events(s) associated with it. The way we do this is characteristically aesthetic in nature, though. In many cases, we could enhance our memory of the same content by reading Wikipedia or a well-written biography. With a memorial, however, we preserve and enhance our memory not just by reading some associated content but by adopting an attitude of attention towards the memorial that treats the memorial for a brief time as an object of final value, as merely worthy of attention for its own sake. We allow our attention to be guided and directed by the memorial and subject ourselves to it, and in doing so we become aware of the aesthetic experience it has to offer that can accomplish its function much differently and more meaningfully than most any biography.

What's important to recognize is that we have the agential capacity to temporarily treat objects as worthy of attention for their own sake, even as we're latently aware of what we're trying to get from them. That is, we can act like an object has final value even while we're trying to extract some instrumental value from it. This entails the capacity for a kind of agential layering, one layer of agency treating an object as a final end and another layer of agency treating it as a means to an end. This is similar to how, in playing a game, we pursue the goals of the game as if they had final value, even as we retain our agency in matters external to the game (so that if an emergency arises, or the cookies are done in the oven, or the game isn't really accomplishing what we wanted it to for our ends or those of the group, we can quit mid-pursuit). ${ }^{20}$ In much of our life with art we do consider the work of art as an end in itself. This was the insight of those who thought art was to be pursued for its own sake. But much art is pursued for other ends. It's just that while we're pursuing those ends we characteristically

20. Nguyen (2020), especially Chapter 3, introduces the idea that we have a capacity for layered agency, especially with respect to games. See also van der Berg (2019) for a discussion of how our attitudes towards games can help us understand the motivational structure of aesthetic appreciation. 
treat the artwork like it's an object of final value. Treating it this way turns out to be essential to accomplishing those further ends.

What the Aesthetic Engagement Theory says when fully unpacked, then, is that something is a work of art iff it has a function, and the fulfillment of that function requires aesthetic engagement with the work. Aesthetic engagement with the work requires attending to the aesthetic properties of the attentive focus specified by the work, so that one treats the focus as worthy of attention for its own sake, but such that one's attention is ultimately guided by one's interaction with the artwork in a way that's directed towards the fulfillment of its function.

The Aesthetic Engagement Theory has a much better claim to extensional adequacy than other aestheticist theories of art. First, it isn't susceptible to a problem of broadness. Recall what were some proposed counterexamples in this neighborhood for Zangwill's Creative Theory: mass-produced industrial appliances (like cars or toasters), a particularly insightful instance of interior decoration, and even everyday hygienic or fashion choices made in order to look good. I'll show briefly how the Aesthetic Engagement Theory avoids these particular examples, since doing so will reinforce the claim that it avoids a problem of broadness, and it will also help to illustrate how to apply the theory in particular cases.

Take cars and toasters first. Unlike Zangwill (and a few others), I don't think these are art (at least not run of the mill cars like my 2007 Toyota Highlander). Thankfully, though, it's pretty obvious that the Aesthetic Engagement Theory will have this result. The Aesthetic Engagement Theory requires there to be an aesthetic condition on the fulfillment of the function of a work of art, but there isn't any such condition on the fulfillment of the function of mass-produced cars or toasters. Cars are for driving. Toasters are for toasting. You can drive a car or toast your toast without paying any attention to the aesthetic properties of the car or the toaster (nor does there seem to be any distinct attentive focus to which these artifacts direct us).

Consider, next, an insightful instance of interior decoration. On the Creative Theory, a well-decorated living room is a work of art if only the decoration is the result of the right kind of aesthetic insight. The Aesthetic Engagement Theorist will say, "not so fast." First, what's the function of this well-decorated living room? It may, of course, be hard to say, in real cases, but since this is our thought experiment we'll stipulate it as we like, seeing how tough we can make things for the Aesthetic Engagement Theory. Say the function of the living room is just to be a space for some mundane activities to occur. In that case it surely won't follow by the Aesthetic Engagement Theory that the living room is a work of art. Say instead that the function of the living room is to be a relaxing and visually pleasing place to gather. Even in this case, it doesn't seem like the 
living room will count as art, since it can fulfill this function for a subject (relaxing them and being visually pleasing for them) automatically, that is, without their actively attending to the features of the room. In that case, the function of the room can be fulfilled without any aesthetic engagement by its subjects. Last try: say the function of the room is to be an object of aesthetic contemplation. That is, it was actually decorated with the intention that those who gather there treat the room as an object worthy of attention and contemplation. In that case, it seems like the Aesthetic Engagement Theory will rule that the living room is art, but in that case it also seems that the living room will be art. The living room is for aesthetic contemplation, we've supposed. A view that denied it art-status in that case would seem to have erred in the other direction. The upshot here is that art status goes hand in hand with object function on the Aesthetic Engagement Theory, and that's a big part of what helps the theory attain extensional adequacy.

Consider, finally, hygienic or fashion choices. On the Creative Theory, a particular act of shaving or putting on a nice shirt can count as a work of art (a performance perhaps) if done with the right kind of aesthetic insight, for example, that it will make one more attractive. Of course, we often consider the aesthetic properties that certain hygienic or fashion choices will endow us with, so in those domains it seems that the Creative Theory vastly overproliferates artistic performances. In many cases (such as with whitened teeth, makeup, or nicely patterned ties), it also seems as if there's no plausible function we can specify for the object besides an aesthetic one. People whiten their teeth because they want others to notice, they want their makeup to improve others' impression of their looks, and they want people to notice and like their ties. It might seem like the Aesthetic Engagement Theory falls prey to the same problem here, then, of overproliferating artworks in the domains of hygiene or fashion. This is not so. To see why, recall my claim that what's common across cases of aesthetic engagement is that one's attention is directed to the aesthetic properties of the attentive focus of the work in such a way that the attentive focus is treated as an end in itself. It must be exceedingly rare for fulfillment of the function of some hygienic or fashion choice to require that others interact with the associated attentive focus as an end in itself. We don't want people to interact with our hygiene or fashion choices that way, since in most cases these choices are merely ornamental. It's one thing to notice someone's nice white teeth. It's entirely another to contemplate the teeth as if the person isn't even there. It's one thing to find someone's makeup to be aesthetically pleasing. It's another to stare at their makeup as if their face is a canvas. It's one thing to say, "Hey, nice tie." It's another to attend to a tie like it contains unseen depths. Clearly I can't enumerate every potential case of non-art and show how the Aesthetic Engagement Theory rules it out, but my hope is that detailing a few such cases 
illustrates how the Aesthetic Engagement Theorist seeks to avoid a problem of broadness.

The Aesthetic Engagement Theory also isn't susceptible to a problem of narrowness. It counts avant-garde artworks like readymades and conceptual art as art. What's important to recognize about these kinds of works is that even though their functions are different from those of traditional artworks, the fulfillment of the functions of readymades and conceptual art requires aesthetic engagement. Let's think about an example of each to see that this is so. Take Duchamp's Fountain. The function of Fountain, we can stipulate, is to expand people's conception of what art can be and direct their attention away from the importance of the aesthetic to the conceptual for the domain of art. ${ }^{21}$ Since Fountain is meant to direct our attention away from the aesthetic dimension of artworks, it would be easy to assume that it does not itself demand aesthetic engagement. That's not the case, though. Consider what distinguishes Fountain from an academic treatise arguing that artworks needn't be aesthetically distinct from everyday objects. Both Fountain and the academic treatise might (or might not) convince us of the same points, but Fountain does so (if at all) by presenting us with an aesthetically mundane object and prescribing that we attend to it. To get the point of Fountain in the manner the work is meant to elicit, one must aesthetically engage the work.

Another kind of challenge for aestheticism has been from conceptual art. Take, for example, Robert Barry's All the things I know but of which I am not at the moment thinking - 1:36 PM; June 15, 1969. The work has been embodied in various places, the eponymous statement having been inscribed on walls and pieces of paper. It's often thought that the work of conceptual art is not identical to any physical object or embodiment, but to an idea, viz. the idea the artist makes salient by presenting some physical object or an idea that's represented or embodied in the physical objects associated with the work. Barry's work might plausibly be thought to be identical to an idea. If so, this might seem to constitute a counterexample to the Aesthetic Engagement Theory, since it might seem that ideas are not the sort of things we can aesthetically engage. I have a couple things to say in response here.

First, we have plenty of reason to see ideas as the kinds of things we can aesthetically engage. Shelley (2003), Schellekens (2007), and Goffin (2019) all argue that we can rightly attribute aesthetic properties to non-perceptible artworks like conceptual art and literature. We're all familiar with the idea that a story, a mathematical proof, a theory, an idea, or any number of things that don't admit of perceptual engagement can have aesthetic properties. They can be beautiful, novel, compelling, or elegant. (Indeed, elegance and beauty are oft-cited theoretical

21. If the function is not exactly this it's something nearby. 
virtues: they are aesthetic reasons some invoke for choosing one theory over another.) Moreover, we are capable of aesthetic engagement with such works. There's no special bar to aesthetic engagement posed by conceptual art. Insofar as aesthetic engagement requires attention, and attention can be directed to imperceptible objects, conceptual art is a candidate for aesthetic engagement.

If you don't like the idea that non-perceptible objects can have aesthetic properties, though, here's another thought that might placate you. Remember Nguyen's distinction between the work and the attentive focus. Conceptual art clearly functions differently than non-artistic communication. Someone writing out the idea behind Barry's All the things I know but of which I am not at the moment thinking - 1:36 PM; June 15, 1969 would not have successfully embodied Barry's work. A plausible explanation of this is that the work prescribes attention (in the form of aesthetic engagement) to one's own experience of the contemplation of the idea that is the work. That is, the work of conceptual art might be an idea, but what is prescribed is that one attend to the aesthetic properties of one's experience of contemplating that idea. The plausibility of this account for a given theorist will depend in part on whether they accept an account of introspection that makes it analogous to perception, so that introspected mental states can plausibly have aesthetic properties in a way like how perceptible objects do. I don't endorse this account, but it's plausible and worth consideration for someone who finds the account I endorsed above untenable.

We also wanted a theory of art that avoided arbitrariness. To avoid arbitrariness, a theory has to ground art-status at least in part in how the work is in itself, rather than grounding it merely in facts about how the work has been regarded by people. The Aesthetic Engagement Theory clearly avoids arbitrariness. It grounds art-status in a higher-level feature of the functions of works of art. Works can have functions with this feature even if people are unaware of that fact or don't believe they do.

Finally, we wanted a theory of art that helped explain why art is valuable as art, that is, what is distinctively valuable about art. The Aesthetic Engagement Theory suggests such an account: art is valuable because it promotes aesthetic engagement. The experience of being aesthetically engaged is distinctive and intrinsically valuable. The insight of the Aesthetic Engagement Theory is that even though aesthetic engagement is intrinsically valuable, we can pursue it as a means to other ends.

\section{Conclusion}

The Aesthetic Engagement Theory says that artworks are objects that demand aesthetic engagement. They are objects with functions the fulfillment of which 
requires that one aesthetically engage the object. Aesthetic engagement involves attending to the aesthetic properties of the attentive focus specified by the work, such that one treats the attentive focus immediately as an object of final value, even while one's attention is ultimately being directed by the goal of fulfilling the function of the work. The Aesthetic Engagement Theory illuminates an important capacity for agential layering, that is, a capacity to treat an object as a locus of instrumental value with one layer of agency while simultaneously treating the object as a locus of final value with another, nested layer of agency. To fulfill the function of an artwork often requires that we treat the artwork as a source of instrumental value (e.g., as a source of knowledge, or as a meditative focus) even while simultaneously subjecting ourselves to it as if it were an object of final value.

I've contrasted the Aesthetic Engagement Theory both with some other versions of aestheticism and with a version of institutionalism. Traditional aestheticist theories suffer from problems of extensional adequacy. They are insufficiently broad, narrow, or both. Institutionalism, on the other hand, seems to make art-status arbitrary. This is an unavoidable consequence of making artworks the products of institutions. Abell's particular version of institutionalism suffers two additional problems. First, it employs an objectionable understanding of art institution, one which seems to face its own problem of extensional adequacy. Second, Abell's theory can't explain what's valuable about art, since it chalks up the value of individual artworks entirely to what they can contribute to the health of the art institutions of which they're products.

The Aesthetic Engagement Theory avoids the pitfalls common to these other theories. It passes a test of extensional adequacy typically failed by other aestheticist theories of art. It makes art-status non-arbitrary. It also provides us with an account of what's distinctively valuable about art. Any new account of art will of course be met with a healthy push of skepticism. The Aesthetic Engagement Theory deserves careful consideration, though. It makes sense of the idea that art is a unified phenomenon even as artworks have a diverse array of functions. Artworks are for all kinds of ends, but all of those ends demand aesthetic engagement.

\section{Acknowledgements}

Thanks to Tim Juvshik, Justin Mooney, and two anonymous referees at Ergo for their helpful comments. Thanks also to the students in my Spring 2017 and Spring 2020 Philosophy of Art courses at UMass Amherst for the quality discussions that contributed to the theory presented in this paper. 


\section{References}

Abell, Catharine (2012). Art: What It Is and Why It Matters. Philosophy and Phenomenological Research, 85(3), 671-91.

Adajian, Thomas (2018). The Definition of Art. In Edward N. Zalta (Ed.), Stanford Encyclopedia of Philosophy (Fall 2018 ed.). Retrieved from https://plato.stanford.edu/archives/ fall2018/entries/art-definition/

Baxandall, Michael (1988). Painting and Experience in Fifteenth Century Italy (2nd ed.). Oxford University Press.

Beardsley, Monroe (1982). The Aesthetic Point of View. Michael J. Wreen and Donald M. Callen (Eds.). Cornell University Press.

Carroll, Noël (1999). Philosophy of Art: A Contemporary Introduction (2nd ed.). Routledge.

Cummins, Robert (1975). Functional Analysis. The Journal of Philosophy, 72(20), 741-65.

Davies, David (2004). Art as Performance. Blackwell Publishing.

Davies, Stephen (1991). Definitions of Art. Cornell University Press.

Davies, Stephen (2016). The Philosophy of Art (2nd ed.). Wiley Blackwell.

De Clercq, Rafael (2002). The Concept of an Aesthetic Property. The Journal of Aesthetic and Art Criticism, 60(2), 167-76.

De Clercq, Rafael (2009). The Aesthetic Creation Theory of Art. Sztuka i Filozofia, 35, 20-24.

Dickie, George (1974). Art and the Aesthetic: An Institutional Analysis. Cornell University Press.

Dickie, George (1984). The Art Circle. Haven.

Dodd, Julian (2017). What 4'33" Is. Australasian Journal of Philosophy, 96(4), 629-41.

Eldridge, Richard (1985). Form and Content: An Aesthetic Theory of Art. The British Journal of Aesthetics, 25(4), 303-16.

Evnine, Simon J. (2013). Ready-Mades: Ontology and Aesthetics. British Journal of Aesthetics, 53(4), 407-23.

Evnine, Simon J. (2016). Making Objects and Events. Oxford University Press.

Gaut, Berys (2000). "Art" as a Cluster Concept. In Noël Carroll (Ed.), Theories of Art Today (25-44). University of Wisconsin Press.

Goffin, Kris (2019). The Affective Experience of Aesthetic Properties. Pacific Philosophical Quarterly, 100(1), 283-300.

Irvin, Sherri (2008). The Ontological Diversity of Visual Artworks. In Kathleen Stock and Katherine Thomson-Jones (Eds.), New Waves in Aesthetics (1-19). Palgrave Macmillan.

Iseminger, Gary (2004). The Aesthetic Function of Art. Cornell University Press.

Juvshik, Tim (2020). Are Artworks Necessarily Artifacts? Unpublished manuscript.

Juvshik, Tim (2021). Function Essentialism about Artifacts. Philosophical Studies. Advance online publication. https://doi.org/10.1007/s11098-020-01594-w

Khalidi, Muhammad Ali (2015). Three Kinds of Social Kinds. Philosophy and Phenomenological Research, 90(1), 96-112.

Krohs, Ulrich and Peter Kroes (Eds.) (2009). Functions in Biological and Artificial Worlds. MIT Press.

Lena, Jennifer C. (2012). Banding Together: How Communities Create Genres in Popular Music. Princeton University Press.

Levinson, Jerrold (1979). Defining Art Historically. British Journal of Aesthetics, 19(3), 232-50. 
Mag Uidhir, Christy (2013). Art and Art Attempts. Oxford University Press.

Millikan, Ruth Garrett (1984). Language, Thought and Other Biological Categories. MIT Press.

Millikan, Ruth Garrett (1995). In Defense of Proper Functions. In White Queen Psychology and Other Essays for Alice (13-29). MIT Press.

Millikan, Ruth Garrett (1999). Wings, Spoons, Pills, and Quills: A Pluralist Theory of Function. The Journal of Philosophy, 96(4), 191-206.

Munro, Thomas (1967). The Arts and Their Interrelations. The Press of Western Reserve University.

Nguyen, C. Thi (2019). Autonomy and Aesthetic Engagement. Mind, 129(516), 1127-56.

Nguyen, C. Thi (2020). Games: Agency as Art. Oxford University Press.

Preston, Beth (2009). Philosophical Theories of Artifact Function. In Anthonie Meijers (Ed.), Philosophy of Technology and Engineering Sciences (213-33). Elsevier.

Riggle, Nicholas Alden (2010). Street Art: The Transfiguration of the Commonplaces. The Journal of Aesthetics and Art Criticism, 68(3), 243-57.

Schellekens, Elisabeth (2007). The Aesthetic Value of Ideas. In Peter Goldie and Elisabeth Schellekens (Eds.), Philosophy and Conceptual Art (71-91). Oxford University Press.

Searle, John (1995). The Construction of Social Reality. Penguin.

Shelley, James (2003). The Problem of Non-Perceptual Art. British Journal of Aesthetics, $43(4), 363-78$.

Sibley, Frank (1959). Aesthetic Concepts. Philosophical Review, 68(4), 421-50.

Sibley, Frank (1965). Aesthetic and Nonaesthetic. Philosophical Review, 74(2), 135-59.

Stecker, Robert (1996). Artworks: Definition, Meaning, Value. Penn State University Press. van der Berg, Servaas (2019). The Motivational Structure of Appreciation. The Philosophical Quarterly, 69(276), 445-66.

Wolterstorff, Nicholas (2015). Art Rethought. Oxford University Press.

Wright, Larry (1973). Functions. Philosophical Review, 82(3), 139-68.

Zangwill, Nick (1995a). Groundrules in the Philosophy of Art. Philosophy, 70(274), 533-44.

Zangwill, Nick (1995b). The Creative Theory of Art. American Philosophical Quarterly, 32(4), 307-23. 